\title{
Role of pRIFLE and AKIN Criteria for Diagnosis of Neonatal Acute Kidney Injury in a Special Care Baby Unit (SCABU)
}

\author{
TAHMINA FERDAUS ${ }^{1}$, SHIREEN AFROZ², MOHAMMAD HANIF ${ }^{3}$, MD ABID HOSSAIN MOLLAH $^{4}$, \\ MANISHA BANERJEE ${ }^{5}$, TOFFAZOL HOSSAIN KHAN ${ }^{6}$
}

\begin{abstract}
Background: The present study was intended to make a comparison of acute kidney injury (AKI) diagnosed and classified by two diagnostic modalities such as paediatric Risk Injury Failure Loss of End Stage Renal Failure (pRIFLE) criteria and acute kidney injury network (AKIN) staging .

Methodology: A total 44 neonates (from 3-28 days) with AKI as case and other 26 neonates without AKI as control were also included in the study. Both were admitted in special care baby unit (SCABU) Dhaka Medical College Hospital.

Results: The neonate of $\leq 7$ days old comprised the main bulk. Majority of the neonates were of average birth weight. The diagnosis was based on estimated creatinine clearance (eCCL) criteria of pRIFLE showed that $40.9 \%$ neonates were at risk of AKI, $20.5 \%$ have had already injured. Higher proportions of neonates were classified as failure (38.6\%). The diagnosis was based on Serum creatinine criteria of AKIN showed that about $64 \%$ of the neonates were at AKI-stage I, $22.7 \%$ at stage-II and $13.6 \%$ at stage-III. Higher proportions of neonates were classified as stagel.We found moderate agreement between pRIFLE criteria and AKIN staging, these two diagnostic modalities for diagnosis of AKI by kappa- statistics. Outcome of neonatal AKI predicted by $p R I F L E$ criteria was significantly higher compared to AKIN staging $(p<0.001)$ in respect to SCABU stay, multiorgan failure, need for dialysis. Here $43 \%$ neonates with AKI were improved with normal renal function and $16 \%$ improved with impaired renal function. Increased frequency of death (34\%) in this series was due to multiorgan involvement with acute kidney failure (AKF). Mortality was significantly higher $(p=0.03)$ in failure group by pRIFLE criteria compared to AKIN stage III. So it is evident that pRIFLE criterions are highly sensitive to classify AKI, it is also superior to AKIN staging in predicting early diagnosis, need for intervention and immediate outcome.

Conclusion: The study concluded that pRIFLE criteria and AKIN staging are useful in the diagnosis of AKI in neonates and pRIFLE criteria are fairly sensitive for better characterization of $A K I$.
\end{abstract}

Key words: neonatal AKI, pRIFLE, Outcome

1. Resident Medical Officer, Critical Care Nephrology and Dialysis Unit, Department of Paediatric Nephrology, Dhaka Shishu (Children) Hospital

2. Professor, Critical Care Nephrology and Dialysis Unit, Department of Paediatric Nephrology, Dhaka Shishu (Children), Hospital, Dhaka

3. Professor \& Head, Department of Paediatric Nephrology, $\mathrm{BICH} \&$ Dhaka Shishu (Children) Hospital

4. Professor, Department of Paediatrics, Ibrahim Medical College \& BIRDEM Hospital, Dhaka.

5. Professor, Department of Neonatology, Dhaka Medical College Hospital, Dhaka.

6. Associate Professor, Department of Neonatology, Dhaka Medical College Hospital, Dhaka

Correspondence: Dr. Tahmina Ferdaus, Resident Medical Officer, Critical Care Nephrology and Dialysis Unit, Department of Paediatric Nephrology, Dhaka Shishu (Children) Hospital, Cell. O1712915986, Email: tahmina34sbmc@gmail.com

Received: 07 August $2017 \quad$ Accepted: 14 November 2017

\section{Introduction}

Acute kidney injury (AKI) occurs in as many as $8 \%$ of neonates admitted in to neonatal intensive care units. Most often, Acute kidney injury (AKI) is recognized because of oliguria (urinary flow rate less than $1 \mathrm{ml} /$ $\mathrm{kg}$ per hour) although nonoliguric neonatal AKI is being detected with increasing frequency ${ }^{1}$. The mortality of oliguric neonatal renal failure may be as high as $60 \%$ in $\mathrm{AKI}$ and even higher in neonates with congenital heart disease, or with anomalies of the genitourinary system ${ }^{1}$.

The cause of AKI is multifactorial ${ }^{2}$. The short-term outcome of $\mathrm{AKI}$ in newborns is highly dependent on 
the underlying etiology, the condition of other organs, and the facilities for renal replacement therapy. Mortality is more frequent and morbidity is much worse in neonates with multiorgan failure ${ }^{3}$. A substantial rise in Serum creatinine and a drop in urine output have been used to determine AKI in neonate. The Acute Dialysis Quality Initiative (ADQI) Group has published a consensus definition and classification system for acute kidney injury (AKI) termed the pRIFLE criteria (risk, injury, failure, loss, and end-stage) ${ }^{4}$. The first 3 categories (risk, injury, and failure) staged the degree of AKI based on whether the amplitude of Serum creatinin rise (or decreased in estimated GFR) and/or a drop in urine output ${ }^{5}$. The last two categories (loss and end-stage) defined temporary or permanent loss of kidney function after $A K I^{5}$. The Kidney Disease Improving Global Outcomes (KDIGO) has brought together international experts from many different specialties to introduce a definition and staging system which will harmonize these recent definitions ${ }^{6}$. These classification definition of pediatric AKI by pRIFLE ,estimated creatinine clearance (eccl) by Schwartz formula and urinary output Risk $(<0.5$ $\mathrm{ml} / \mathrm{kg} / \mathrm{h}$ for $8 \mathrm{hrs}$ ), Injury ( $<0.5 \mathrm{ml} / \mathrm{kg} / \mathrm{h}$ for $16 \mathrm{hrs})$, Failure ( $<0.3 \mathrm{ml} / \mathrm{kg} / \mathrm{h}$ for 24 or anuria for $12 \mathrm{hrs}$. The Acute Kidney Injury Network (AKIN) group has recently proposed neonatal acute kidney injury classification definition (AKIN staging) ${ }^{7}$

Stage i : SCr $>0.3 \mathrm{mg} / \mathrm{dl}$ or SCr> $150-200 \%$ from baseline

Stage ii : SCr>200\%-300\% from baseline

Stage iii : SCr of $>300 \%$ from baseline or SCr $>4.0$ $\mathrm{mg} / \mathrm{dll}$ with an acute rise of at least $0.5 \mathrm{mg} / \mathrm{dl}$

Using these definitions, we have been able to find an independent predictor of mortality in ill neonates ${ }^{8}$, even after controlling for co-morbidities, interventions and demographics. Even small changes in serum creatinine which were previously ignored, may be associated with poor outcome ${ }^{9}$. The present study was intended to determine the role of pRIFLE criteria and AKIN staging in diagnosing and predicting the outcome by early diagnosis and interventions of neonatal AKI. The findings obtained from the study would help us to institute early and effective intervention in neonatal $\mathrm{AKI}$ in order to prevent further progression of the disease and to reduce mortality and morbidity.

\section{Methodology:}

This observational study was carried out in the Special Care Baby Unit (SCABU) of Dhaka Medical College Hospital, Dhaka from October 2013 to March 2014. All sick neonates (aged 3-28 days) admitted in SCABU and fulfilled the predefined eligibility criteria of AKI were the study population. A total of 44 neonates with AKI were included in the study as cases. AKI was suspected when urinary output was reduced $<0.5 \mathrm{ml} /$ $\mathrm{kg} / \mathrm{hr}$ and increasing serum creatinine with or without reduced output $<0.5 \mathrm{ml} / \mathrm{kg} / \mathrm{hr}$. Then classified by using pRIFLE criteria and AKIN staging. Twenty six neonates without AKI were only included as control to see the efficacy of pRIFLE diagnosing criteria of AKI. Patients with congenital anomalies. obstructive uropathy and parents unwilling to allow their neonates to participate were excluded. Prior permission was taken for this study from the Ethical Committee of Dhaka Medical College Hospital, Dhaka, Bangladesh. Written informed consent was obtained from each parents/ attendants. All precautions were taken to protect the anonymity of the participating subjects. Urine was collected by urine collecting adhesive bag, and was recorded as per kilogram of body weight per hour in follow up sheets. After $3^{\text {rd }}$ day of admission when urinary output was reduced then $2 \mathrm{ml}$ blood sample was taken for serum creatinine criteria of AKI. Baseline serum creatinine was considered $0.3 \mathrm{mg} / \mathrm{dl}$.Serum creatinine considered noted when raised $>0.3 \mathrm{mg} / \mathrm{dl}$ or raised 1.5-2 folds from the base line. By Schwartz formula estimated creatinine clearance $(\mathrm{eCCl})$ was calculated $\{i, e(e C C l=k \times$ Lenght $(\mathrm{cm}) / S$.creatinine $)$ where $\mathrm{k}$ for preterm $=0.27$ and for term $=0.37$. According to pRIFLE criteria neonates with impaired renal function were classified as Risk, Injury ,Failure group on the basis of eCCL and urine output. According to AKIN staging acute kidney injury classified as stage I, stage II, stage III on the basis of serum creatinine and urine output .

\section{Operational definitions}

Acute kidney injury classification: Paediatric RIFLE criteria ${ }^{10}$

\begin{tabular}{lll}
\hline & Estimated creatinine clearance(eCCL) & Urine output \\
\hline Risk (stage-1) & eCCl decreased by $25 \%$ & $<0.5 \mathrm{ml} / \mathrm{kg} / \mathrm{hr}$ for $8 \mathrm{hrs}$ \\
Injury (stage-2) & eCCl decreased by $50 \%$ & $<0.5 \mathrm{ml} / \mathrm{kg} / \mathrm{hr}$ for $16 \mathrm{hrs}$ \\
Failure (stage-3) & eCCl decreased by $75 \%$ & $<0.3 \mathrm{ml} / \mathrm{kg} / \mathrm{hr} 24 \mathrm{hrs}$ or anuria for $12 \mathrm{hrs}$ \\
Loss (stage-4) & Persistent failure for $>4$ weeks & \\
End-stage (stage-5) & Persistent failure $>3$ month & \\
\hline
\end{tabular}




\section{Proposed neonatal acute kidney injury Staging by AKIN criteria ${ }^{11}$}

Stage I. $\uparrow S C r>0.3 \mathrm{mg} / \mathrm{dl}$ or $\uparrow S C r>150-200 \%$ from baseline

Stage II. $\uparrow S C r>200-300 \%$ from baseline

Stage III. $\uparrow S C r$ of $>300 \%$ from baseline or $\mathrm{SCr}>4.0$ $\mathrm{mg} / \mathrm{dl}$ with an acute rise of at least $0.5 \mathrm{mg} / \mathrm{dl}$

eCCL : eCCL or estimated creatinine clearance was measured by Schwartch formula which is as follows:

eCCL $=\frac{k \times \text { Length }^{(12)}}{\text { Sr. Creatinine }}$

Where, $\mathrm{k}($ for preterm $)=0.27, \mathrm{k}=($ for term $)=0.37$

\section{Statistical analysis:}

Using computer software SPSS -16, data were processed and analyzed. The test statistics used to analyze the data were descriptive statistics, Chi-square $\left(\chi^{2}\right)$ or Fisher's Exact Probability Test (for comparison of data presented on categorical scale), ANOVA statistics (for comparison of continuous data among three categories of AKI) and Level of significance was set at $5 \%$ and $<0.05$ was considered significant.

\section{Results :}

Demographic profile among the study population demonstrated that there is no significantly difference of age, sex, birth weight, gestational age between 44 neonates with $\mathrm{AKI}$ and 26 neonates without $\mathrm{AKI}$.

Table-I

Demographic profile among the study populations $(n=44)$ \& control group $(n=26)$

\begin{tabular}{lccc}
\hline & $\begin{array}{c}\text { Case with } \\
\text { AKI }\end{array}$ & $\begin{array}{c}\text { Control with } \\
\text { AKI }\end{array}$ & $\begin{array}{c}\text { P } \\
\text { value }\end{array}$ \\
\hline Age & & & \\
$<7$ days & 28 & 13 & \\
$8-14$ days & 11 & 7 & 0.06 \\
$15-21$ days & 3 & 3 & \\
$>21$ days & 2 & 3 & \\
Sex & & & \\
Male & 21 & 21 & 0.12 \\
Female & 23 & 23 & \\
Birth weight & & & \\
1000-1500 gm & 2 & 2 & 0.76 \\
1500-2500 gm & 10 & 10 & \\
$>2500$ gm & 32 & 14 & \\
Gestational age & & & \\
Preterm & 33 & 6 & 0.92 \\
Term & 11 & 20 & \\
\hline
\end{tabular}

Clinical characteristics were breathing difficulty $(77.3 \%)$ and anemia $(75 \%)$. The next common characteristics were cyanosis $(63.7 \%)$, reluctant to feed $(52.3 \%)$, dehydration (50\%) and convulsion (43.2\%). Other less common symptoms and signs were grunting, fever and distended abdomen.

AKI staging using urine output and estimated creatinine clearance $(\mathrm{eCCL})$ of pRIFLE criteria:

Table - II

Distribution of neonatal AKI by urine output criteria of $p R I F L E$

\begin{tabular}{lcccc}
\hline $\begin{array}{l}\text { Urine output } \\
\text { (ml/kg/hr) }\end{array}$ & \multicolumn{5}{c}{ Time interval } \\
\hline$<0.5 \mathrm{ml} / \mathrm{kg} / \mathrm{hr}$ & $15(34.1)$ & - & $9(20.5)$ & - \\
$<0.3 \mathrm{ml} / \mathrm{kg} / \mathrm{hr}$ & - & - & - & $13(29.5)$ \\
Anuria & - & $7(15.9)$ & - & - \\
\hline
\end{tabular}

Distribution of neonates by their rate of urine output is shown in Table II. Of the 44 neonates, 15(34.1\%) passed urine $(<0.5 \mathrm{ml} / \mathrm{kg} / \mathrm{hr})$ in 8 hours (Risk) and 9(20.5\%) passed the same amount in 16 hours (Injury). About $30 \%$ of the neonates passed $<0.3 \mathrm{ml} / \mathrm{kg} / \mathrm{hr}$ of urine in 24 hours (Failure) and about $16 \%$ did not pass any urine in 12 hours (Failure).

Table- III

Distribution of neonatal AKI by estimated creatinine clearance (eCCL) of pRIFLE criteria $(n=44)$.

\begin{tabular}{lccc}
\hline eCCL & $\begin{array}{c}\text { pRIFLE } \\
\text { classification }\end{array}$ & No & $\%$ \\
\hline Decreased by 25\% & Risk & 19 & 43.2 \\
Decreased by 50\% & Injury & 10 & 22.7 \\
Decreased 75\% & Failure & 15 & 34.1 \\
\hline
\end{tabular}

The diagnosis based on eCCL criteria of pRIFLE shows that $43.2 \%$ neonates were at risk of acute kidney injury, $22.7 \%$ have had already injured and $34.1 \%$ had kidney failure.

AKI by AKIN criteria

Table - IV

Distribution of neonatal AKI by AKIN Criteria $(n=44)$

\begin{tabular}{lccc}
\hline $\begin{array}{l}\text { Increase in serum } \\
\text { creatinine from } \\
\text { baseline }\end{array}$ & $\begin{array}{l}\text { Diagnosis } \\
\text { based on } \\
\text { AKIN }\end{array}$ & No & $\%$ \\
\hline $150-200 \%$ & Stage I & 28 & 63.6 \\
$>200-300 \%$ & Stage II & 10 & 22.7 \\
$>300 \%$ & Stage III & 6 & 13.6 \\
\hline
\end{tabular}

About $64 \%$ of the neonates were at AKI-stage I, $22.7 \%$ at stage-II and $13.6 \%$ at stage-III (Table IV). 
Table - V

Comparison of diagnosis made by AKIN and pRIFLE criteria

\begin{tabular}{lccc}
\hline $\begin{array}{l}\text { Increase in serum } \\
\text { creatinine from } \\
\text { baseline }^{\#}\end{array}$ & $\begin{array}{c}\text { Diagnosis } \\
\text { based on } \\
\text { AKIN }\end{array}$ & $\begin{array}{c}\text { Diagnosis } \\
\text { basedp }\end{array}$ & $\begin{array}{c}\text { p- } \\
\text { value }\end{array}$ \\
\hline Stage I/Risk & $28(63.7)$ & $19(43.2)$ & \\
Stage II/Injury & $10(22.7)$ & $10(22.7)$ & $0.024^{*}$ \\
Stage III/Failure & $6(13.6)$ & $15(34.1)$ & \\
\hline
\end{tabular}

Figures in the parentheses indicate corresponding percentage\# Data were analysed using Chi-Square $\left(\chi^{2}\right)$

Diagnosis of AKI shows that a significantly higher proportion of neonates were classified as Stagelll/ Failure (34.1\%) by using pRIFLE criteria compared to that made by AKIN criteria $(13.6 \%)(p=0.024)($ Table $: V)$.

Consistency between pRIFLE and AKIN in diagnosing AKI:

The strength of agreement between diagnoses of acute kidney injury (AKI) made by pRIFLE and AKIN as revealed by kappa-statistics (k-statistics) ${ }^{*}$ was 0.47 indicating that findings of the two modalities are in moderate agreement $(p=0.003)$.

Table- VI

Agreement between diagnosis made by pRIFLE and $A K I N$

\begin{tabular}{lccccc}
\hline AKIN & \multicolumn{2}{c}{ pRIFLE } & Total & $\begin{array}{c}k- \\
\text { value }\end{array}$ & $\begin{array}{c}p- \\
\text { value }\end{array}$ \\
\hline AKI & 34 & 10 & 44 & & \\
No AKI & 10 & 26 & 36 & 0.47 & 0.003 \\
Total & 44 & 36 & 80 & & \\
\hline
\end{tabular}

*The strength of agreement between two diagnostic tests in diagnosing a particular disease is calculated using kappa statistics ( $\mathrm{k}$-value), whereby a kappa value of $<0.4$ indicates poor agreement, $0.41-0.60$ moderate agreement, $0.61-0.80$ good agreement and $0.81-1.0$ very good agreement.

Table - VII

Outcome of different classes of AKI by pRIFLE criteria $(n=44)$

\begin{tabular}{lcccc}
\hline Outcome variables & pRIFLE & F- & value \\
& Risk $(\mathrm{n}=19)$ & Injury $(\mathrm{n}=10)$ & Failure $(\mathrm{n}=15)$ & $<0.001$ \\
SCABU stay* (days) & $4.7 \pm 0.5$ & $4.8 \pm 0.4$ & $12.1 \pm 7.9$ & 0.026 \\
Multi organ failure $^{\#}$ & $1(5.6)$ & $4(44.4)$ & $7(41.2)$ & $<0.001$ \\
Dialysis needed & $0(0.0)$ & $0(0.0)$ & $15(88.2)$ & 0.885 \\
Resolution from AKI $^{\#}$ & $7(38.9)$ & $4(44.4)$ & $8(47.1)$ & 0.106 \\
Mortality $^{*}$ & $2(11.1)$ & $3(33.3)$ & $7(41.2)$ & \\
\hline
\end{tabular}

*Data were analysed using ANOVA statistics and were presented as mean \pm SD.

\# Data were analysed using Chi-square Test $\left(\chi^{2}\right)$ and were presented as $n(\%)$.

There was no difference between risk and injury in terms of scabu stay. However, failure group had a significantly longer stay compared to risk and injury Group $(p<0.001)$. Multiorgan failure was found to be lower in the risk group compared to other two groups $(p=0.026)$. Majority of the failure group needed dialysis as compared to the risk and injury group $(p<0.001)$. The resolution from AKI was almost similar among the group $(p=0.885)$. The mortality was progressively higher from risk to failure Groups $(p=0.106)$ (Table VII).

Table VIII

Outcome of different stages of AKI diagnosed by AKIN criteria $(n=44)$

\begin{tabular}{lcccc}
\hline Outcome variables & & AKIN & p-value \\
& Stage I $(\mathrm{n}=28)$ & Stage II $(\mathrm{n}=10)$ & Stage III $(\mathrm{n}=6)$ & \\
\hline scabu stay* $^{*}$ & $4.8 \pm 0.6$ & $13.1 \pm 7.9$ & $11.2 \pm 8.9$ & $<0.001^{*}$ \\
Multi organ failure $^{*}$ & $5(17.9)$ & $6(60.0)$ & $1(16.6)$ & 0.030 \\
Dialysis needed\# & $2(7.1)$ & $8(80.0)$ & $5(83.3)$ & $<0.001^{*}$ \\
Resolution from AKI\# & $12(42.9)$ & $3(30.0)$ & $4(66.7)$ & 0.357 \\
Mortality $^{\#}$ & $5(17.9)$ & $6(60.0)$ & $1(16.7)$ & 0.006 \\
\hline
\end{tabular}

*Data were analysed using ANOVA statistics and were presented as mean \pm SD. 
\# Data were analysed using Chi-square Test $\left(\chi^{2}\right)$ and were presented as $\mathrm{n}(\%)$. The scabu stay was shortest in stage-I and longest in stage-II disease, while that in stage-III was in between them $(p<0.001)$. Multiorgan failure was highest in the stage-Il compared to other two groups $(p=0.030)$. Majority of the stageII and stage-III diseases needed dialysis as opposed to stage-I $(p<0.001)$. The groups however, did not differ with respect to resolution from AKI $(p=0.357)$. The mortality was significantly higher in stage-II compared to stage-I and stage-III diseases $(p=0.006)$ (table VIII).

Table IX

Predicted outcome (resolution from AKI) pRIFLE criteria:

\begin{tabular}{lccc}
\hline $\begin{array}{l}\text { pRIFLE } \\
\text { stages }\end{array}$ & $\begin{array}{c}\text { Improved with } \\
\text { normal Renal } \\
\text { function }\end{array}$ & $\begin{array}{c}\text { Improved with } \\
\text { impaired renal } \\
\text { function }\end{array}$ & Death \\
\hline Risk & 7 & 0 & 2 \\
Injury & 4 & 0 & 3 \\
Failure & 8 & 3 & 7 \\
\hline Total & $19(43 \%)$ & $3(3.8 \%)$ & $12(27 \%)$ \\
\hline
\end{tabular}

Over all $27 \%$ of the neonates diagnosed as AKI died of the disease, $43 \%$ improved with normal renal function and only $6.8 \%$ improved with impaired renal function (table : IX).

Table $\mathbf{X}$

Predicted outcome (resolution from AKI) AKIN staging

\begin{tabular}{lccc}
\hline AKIN \\
staging & $\begin{array}{c}\text { Improved with } \\
\text { normal renal } \\
\text { function }\end{array}$ & $\begin{array}{c}\text { Improved with } \\
\text { impaired renal } \\
\text { function }\end{array}$ & Death \\
\hline Stage I & 12 & 0 & 5 \\
Stage II & 3 & 2 & 6 \\
Stage III & 4 & 5 & 1 \\
\hline Total & $19(43 \%)$ & $7(3.1 \%)$ & $12(5.3 \%)$ \\
\hline
\end{tabular}

Over all $5.3 \%$ of the neonates diagnosed as AKI died of the disease, $43 \%$ improved with normal renal function, $3.1 \%$ improved with impaired renal function ( table : $\mathrm{x}$ ).
Table XI

Distribution of neonates who are needed intermittent peritoneal dialysis both AKIN staging and $p R I F L E$ criteria :

\begin{tabular}{ll}
\hline AKIN staging & Intermittent Peritoneal Dialysis \\
\hline Stage II & $8(53.3 \%)$ \\
Stage III & $7(33,3 \%)$ \\
\hline pRIFLE criteria & Intermittent Peritoneal Dialysis \\
\hline Injury & $0(0.0 \%)$ \\
Failure & $15(100 \%)$ \\
\hline
\end{tabular}

Likewise 15 neonates were diagnosed as acute kidney failure by pRIFLE and all of them needed intermittent peritoneal dialysis. Whereas only 7 neonates of them were categorized as stage-III and 8 neonates in stage II by AKIN criteria all of them needed IPD (table XI).So, pRIFLE criteria provides early predictive abilities in diagnosis AKI compared to AKIN staging .

\section{Discussion}

The aims of the present study were to make a comparison of the outcome of neonates with AKI diagnosed and classified by two diagnostic modalities such as pRIFLE and AKIN. The incidence of AKI varies according to the population studied, the level of attention of the hospital center, and the country's level of development ${ }^{13}$.Presently, the tendency is to perceive $\mathrm{AKI}$ as an evo-lutionary spectrum and classify it with scales of severity or stages of AKI like the pRIFLE Scale, which was validated in $2007^{14}$. It has been shown that the incidence of AKI increases when applying the pRIFLE Scale. ${ }^{15}$. Rovetto et al reported the incidence of $\mathrm{AKI}$ in the $\mathrm{nICU}$ is 16 times higher than in general wards, which shows that the risk of $\mathrm{AKI}$ increases as the patient is most critical ${ }^{16}$.

The widespread acceptance of consensus definitions for $A K I$ is reflected in the increased utilization of both pRIFLE and AKIN criteria in the literature. In order to progress further, establishment of a uniform definition for AKI applicable in a variety of patient populations is necessary ${ }^{17}$.

In the present study neonates with AKI or no AKI had no difference in terms of age, sex, \& birth weight. The neonate of d" 7 days old comprised the main bulk.More than two third (68.2)\% of the neonates experienced perinatal asphyxia stage II and stage III, most commonest prerenal cause of $\mathrm{AKI}^{18}$. Moreover second risk group is septicemia (59\%). Among 
maternal risk factors more common is pregnancy induced hypertension and reported in $63.6 \%$ cases.

In comparison to other study there was no difference in age, sex, birth weight for diagnosis of AKI. Majority of causes are septicemia, hypovolemia, hypotension, multi -organ failure, intravascular volume depletion, intraventricular hemorrhage, uses of phototherapy due to increased nitric oxide which causes vasodilatation, hypernatremic dehydration, different nephrotoxic drug users ${ }^{19}$.

In the present study the outcome of AKI in neonates predicted by pRIFLE criteria showed significantly higher number of neonates in failure group with respect to SCABU stay. Multiorgan failure was found to be significantly higher in the failure group.All of the failure group neonates needed dialysis. The mortality was increasingly higher in failure groups.

On the other hand the outcome predicted by AKIN criteria showed that the SCABU stay was shortest in Stage-I and longest in Stage-II and Stage - III . Multiorgan failure was frequently common in the StageII . Majority of the Stage-II and Stage-III needed dialysis. The mortality was significantly higher in Stage-II and Stage III.

Previous study report also suggested that longest SCABU stay with intervention needed in both failure group and stage III. The mortality was significantly higher in stage III 20.

Significantly higher percentage $(60 \%)$ of the neonates diagnosed as acute kidney failure by pRIFLE died of the disease, While only $8.3 \%$ of the dead neonates were diagnosed as stage III disease by AKIN criteria $(p=0.034)$. Likewise 15 neonates were diagnosed as acute kidney failure by pRIFLE, all of them needed intermittent peritoneal dialysis, where as only 7 $(46.7 \%)$ of them were categorized as stage-III disease by AKIN critera needed IPD.So from these findings it is evident that a pRIFLE criterion is superior to AKIN criteria in the classification of $\mathrm{AKI}$, and early prediction of therapeutic need and outcome.

In comparison to other study only small differences $(<1 \%)$ has been found in the number of patients classified as having some degree of kidney injury using either the AKIN or pRIFLE definition or classification systems. ${ }^{21}$. AKIN slightly increased the number of patients classified as Stage I injury (category $R$ in RIFLE) (from 16.2 to $18.1 \%$ ) but decreased the number of patients classified as having Stage II injury (category I in pRIFLE) (13.6\% versus $10 \%)^{22}$.
The pRIFLE criteria are highly sensitive to classify AKI into risk, injury, and failure. The strength of agreement between the diagnostic modalities as revealed by kappa-statistics was observed to be moderate (0.47) meaning that in the classification of AKI, the two diagnostic modalities will agree in $47 \%$ cases.

Compared to the pRIFLE criteria, the AKIN criteria do not materially improve the sensitivity, robustness and predictive ability of the definition and classification of AKI in the first $24 \mathrm{~h}$ after admission to ICU ${ }^{23}$.

Significantly higher number of neonates $(n=15)$ were classified as failure by pRIFLE compare to neonates $(n=6)$ in AKIN Stage -III. So, a pRIFLE criterion provides early predictive ability in diagnosis of AKI compared to AKIN staging.

Thus a pRIFLE criterion stresses the early requirement of intervention (IPD) and there be superior to AKIN Staging in reducing mortality and morbidity ${ }^{24}$.More neonates (8) in failure group of pRIFLE criteria improved with normal renal function after getting IPD compare to 4 neonates of AKIN stage III. Equal number $(n=7)$ of neonates in failure group and stage II and III groups had improved with impaired renal function after IPD .These group of patient will develop Chronic Kidney Disease in the long run and referred to chronic kidney disease follow up clinic.

So, a pRIFLE criterion is superior to AKIN staging in predicting early diagnosis, need for intervention and outcome.

These consensus criteria for acute kidney injury (AKI) developed by the Acute Dialysis Quality Initiative (ADQI) group, first published in $2004^{29}$ and named with the acronym $\operatorname{pRIFLE}(p=$ pediatric, $R=$ risk, $I=$ injury, $F=$ failure,$L=$ loss of kidney function, and $E=$ endstage renal failure), represent the first concerted effort to overcome the variety of different definitions for AKI. More recently, a modified version was proposed by the Acute Kidney injury Network (AKIN) ${ }^{25}$.

The main focus of comparison is most often the ability of both definition systems to predict outcome. However, this was not the original intention of a consensus definition for AKI. The initial aim was to create a uniform definition to help researchers and ultimately clinicians to classify the extent of renal dysfunction and to improve prophylactic and therapeutic measures ${ }^{26}$. 
The pediatric RIFLE ( $p$ RIFLE) was found to be better in classifying $A K I$ and reflects the course of $A K I$ in neonates admitted to the intensive care unit (NICU) 27. The pediatric RIFLE criterion appear to be quite promising for better characterization of $\mathrm{AKI}$ and has been validated in children, although additional studies are needed to validate this classification further ${ }^{83,88}$. Further validation and utilization of pRIFLE criteria would allow inter-center comparisons to be made of AKI in children. The RIFLE criteria are utilized by the Acute Kidney Injury Network (AKIN), which is a group of adult nephrologists, pediatric nephrologists, critical care physicians and social organizations interested in AKI research; the focus of AKIN is to facilitate international, interdisciplinary and intersociety collaborations to ensure progress in the field of AKI ${ }^{28}$.

\section{Conclusion:}

From the findings of the study it can be concluded that both pRIFLE and AKIN are useful in the diagnosis of AKI in neonates. The strength of agreement between the two diagnostic modalities is moderate. and management of AKI as by pRIFLE criteria we can diagnosis AKI early.

\section{References}

1. Stapleton FB, JonesDP, GreenRS. Acute renal failure in neonates: incedence, eitiology and outcome. Pediatr Nephrolo 1987 Jul ;1 (3): 314 20 .

2. RN Srivastava,,ArvindBagga. Acute kidney injury, paediatric Nephrology . $6^{\text {th }}$ edition Jaypee Brother Medical Published New Delhi 2016; $.235-236$

3. Akcan-Arikan A, Zappitelli M, Loftis LL. Modified RIFLE criteria in critically ill children with acute kidney injury, Kidney Int. 2007; 71: 1028-35.

4. Palmieri T, Lavrentieva A, Greenhalgh D.An assessment of acute kidney injury with modified RIFLE criteria in pediatric patients with severe burns. Intensive Care Med. 2009; 35:2125-9.

5. Nouri S, Mahdhaoui N, Beizig S. Acute renal failure in full term neonates with perinatal asphyxia. Arch Pediatr 2008;15:229-35.

6. Cuzzolin L, Fanos V, Pinna B. Postnatal renal function in preterm newborns. a role of diseases, drugs and therapeutic interventions PediatrNephrol 2006;21:931-8.
7. Askenazi DJ, Griffin R, McGwin G. Acute kidney injury is independently associated with mortality in very low birth weight infants. PediatrNephrol. 2009; 24:991-7

8. Sharon Phillips Andreloi. Acute kidney injury in critically ill newborn. PediatrNephroogy 2009;24:253-263.

9. Mathur NB, Agarwal HS, Maria A. Acute renal failure in neonatal sepsis. Indian J Pediatr. 2006;73:499-502.

10. Subramanian S, Agarwal R, Deorari AK, Paul VK, Bagga A. Acute renal failure in neonates. Indian J Pediatr 2008;75:385-91.

11. Friedlich PS, Evans JR, Tulassay T, Seri I. Acute and chronic renal failure. In: Taeusch HW, Ballard RA, Gleason CA editors. Avery's diseases of the newborn. 8th ed. Philadelphia: Elsevier Saunders 2005; 1298-305.

12. Askenazi. Evaluation and Management of Critically III Children with Acute Kidney Injury. CurrOpin Pediatr.2011; 23:201-207

13. Akcan-Arikan A, Zappitelli M, Loftis LL, Washburn KK, Jefferson LS, Goldstein SL. Modified RIFLE criteria in critically ill children with acute kidney injury. Kidney Int 2007; 71:1028-1035.

14. Rovetto C, Julián A, Cardona S, Andrés F, Juan $F$, de Castaño I. Acute kidney injury applying pRIFLE scale in Children of Hospital Universitario del Valle in Cali, Colombia: clinical features, management and evolution. Colombia Médica 2012; 43(3):200-04.

15. Bellomo R, Ronco C, Kellum JA, Mehta RL, Palevsky P, Acute Dialysis Quality Initiative workgroup: Acute renal failure - definition, outcome measures, animal models, fluid therapy and information technology needs: the Second International Consensus Conference of the Acute Dialysis Quality Initiative (ADQI) Group. Crit Care 2004, 8:R204-R212.

16. Mehta RL, Kellum JA, Shah SV, Molitoris BA, Ronco C, Warnock DG, Levin A, Acute Kidney Injury Network: Acute Kidney Injury Network: report of an initiative to improve outcomes in acute kidney injury. Crit Care 2007; 11: R31.

17. Moghal NE, Brocklebank JT, Meadow SR. A review of acute renal failure inchildren: incidence, 
etiology and outcome. ClinNephrol 1998; 49:9195.

18. Karlowivz MG, Adelman RD. Nonoliguric and oliguric acute renal failure PediatrNephrol 1995; 9:718-722.

19. Aggarwal A, Kumar P, Chowkhary G, Majumdar $S$, Narang A. Evaluation of renal functions in asphyxiated newborns. J Trop Pediatr 2005; 51:295-299.

20. Airede A, Bello M, Werasingher HD. Acute renal failure in the newborn: Incidence and outcome. J Paediatr Child Health 1997; 33:246-249.

21. Cuzzolin L, Fanos V, Pinna B, di Marzio M, Perin M, Tramontozzi P, Tonetto P, Cataldi L. Postnatal renal function in preterm newborns: a role of diseases, drugs and therapeutic interventions. Pediatr Nephrol 2006; 21:931-934.

22. Gouyon JB, Guignard JP. Management of acute renal failure in newborns. PediatrNephrol 2000; 14:1037-1040.

23. Mathew OP, Jones AS, James E, Bland H, Groshong T. Neonatal renal failure: usefulness of diagnostic indices. Pediatrics 1980; 65:5760.

24. Ellis EN, Arnold WC. Use of urinary indexes in renal failure in the newborn. Am J Dis Child 1982; 136:615-617.

25. Basile DP. The endothelial cell in ischemic acute kidney injury: implications for acute and chronic function. Kidney Int 2007;72:151-156.

26. Andreoli SP. Reactive oxygen molecules, oxidant injury and renal disease. PediatrNephrol 1991; 5:733-742

27. Forbes JH, Hewitson TD, Becker GJ, Jones CL. Simultaneous blockage of endothelin A and B receptors in ischemic acute renal failure is detrimental to long term kidney function. Kidney Int 2001; 59:1333-1341.

28. Bagga A, Bakkaloglu A, Devarajan P, Mehta RL, Kellum JA, Shah SV, Molitoris BA, Ronco C, Warnock DG, Joannidis M, Levin A, Acute Kidney Injury Network. Improving outcomes from acute kidney injury: report of an initiative. Pediatr Nephrol 2007; 22:1655-1658. 